\title{
Optimum multi-objective reservoir operation with emphasis on flood control and ecology
}

\author{
R. Dittmann ${ }^{1}$, F. Froehlich ${ }^{2}$, R. Pohl ${ }^{1}$, and M. Ostrowski ${ }^{2}$ \\ ${ }^{1}$ Institute of Hydraulic Engineering and Applied Hydromechanics, Dresden University of Technology, Dresden, Germany \\ ${ }^{2}$ Institute of Hydraulic and Water Resources Engineering, Section of Engineering Hydrology and Water Management, \\ Technical University Darmstadt, Darmstadt, Germany
}

Received: 30 January 2009 - Revised: 13 July 2009 - Accepted: 28 July 2009 - Published: 30 November 2009

\begin{abstract}
The objective is to present a reservoir management system which is capable of determining optimal operating rules both for flood event based and normal operation while at the same time attempting to achieve ecologically oriented operation. In order to maintain the variability of the natural flow regime, a new dynamic operating policy is introduced for normal operation. Flood event based operation is managed by a two-part step function. Both operating policies are optimized using a state-of-the-art multi-objective evolution strategy algorithm.
\end{abstract}

\section{Introduction}

In the low mountain ranges of Germany and other European countries, multipurpose reservoirs play an important role in providing flood protection for downstream areas and serving water supply. Other utilizations are low flow regulation for downstream reaches during dry seasons, hydropower generation and recreation. At the same time, most dams profoundly alter the flow regime of the river on which they are built, which has a damaging effect on a large variety of riverine ecosystem aspects (Poff et al., 1997).

Numerous investigations have examined methods to optimize reservoir policy decisions (Labadie, 2004; Yeh, 1985). The use of evolutionary algorithms (EA) for optimizing reservoir operation has been gaining in popularity since the 1990s (e.g. Oliveira and Loucks, 1997; Sharif and Wardlaw, 2000; Lohr, 2001; Ndiritu, 2005; Chen et al., 2007; Kim et al., 2006). This trend is also due to advances in computer technology, as evolutionary algorithms tend to be computationally intensive.

The objective of this paper is to present a reservoir management system that is capable of determining optimal operating rules both for normal as well as for flood event based operation while at the same time attempting to achieve an ecologically oriented reservoir operation. The optimization system utilizes a state-of-the-art Multi-Objective Evolution Strategy (MOES) algorithm (Muschalla, 2008), and is integrated into the optimization framework BlueM.Opt ${ }^{1}$.

The result of a multi-objective optimization is a Paretooptimal set of solutions, in which each individual solution represents one possible trade-off between the objectives. Prioritization between the objectives is left up to the decisionmaker. The optimization framework uses the state-of-the-art conceptual reservoir and runoff model BlueM.Sim ${ }^{1}$ for performing the simulations.

\section{Case study}

The Weisseritz River Basin, located in the low mountain ranges of eastern Germany and equipped with three multipurpose reservoirs, is used as a case study (see Fig. 1). The reservoir system Lehnmühle-Klingenberg is a serial system and is mainly used for water supply and flood protection. The reservoir Malter is arranged in parallel to the reservoir system Lehnmühle-Klingenberg and is used for recreation, flood protection and hydropower generation. Within the optimization system, hydropower generation is not considered as it is of minor importance in this study.

\footnotetext{
${ }^{1}$ BlueM.Opt and BlueM.Sim are part of the BlueM package: http://www.ihwb.tu-darmstadt.de/bluem/
}

Published by Copernicus Publications on behalf of the European Geosciences Union. 


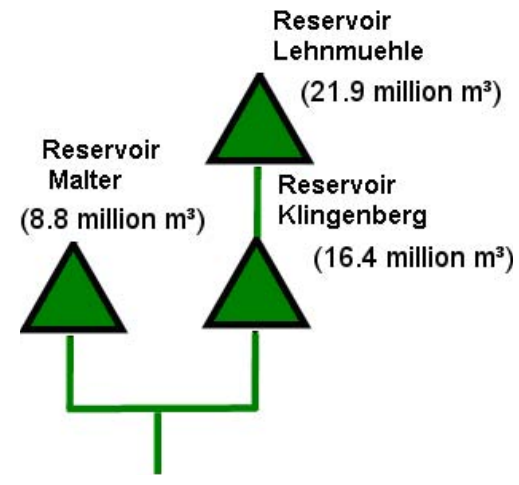

Fig. 1. Schematic view of the reservoir system; maximum storage capacities are indicated.

The downstream releases of the reservoirs depend on the current storage volume:

$Q_{\text {out }}= \begin{cases}Q_{\text {in }} & \left(S>S_{\text {target }} \wedge Q_{\text {in }}<Q_{\text {max }}\right) \bar{\vee}\left(S<S_{\text {min }}\right) \\ Q_{\text {max }} & S>S_{\text {target }} \wedge Q_{\text {in }} \geq Q_{\text {max }} \\ Q_{\text {min }} & S \leq S_{\text {target }}\end{cases}$

where $S\left[\mathrm{~m}^{3}\right]$ is the current storage volume, $S_{\text {target }}\left[\mathrm{m}^{3}\right]$ is the reservoir target level or full supply level, $Q_{\text {out }}\left[\mathrm{m}^{3} / \mathrm{s}\right]$ is the reservoir release, $Q_{i n}\left[\mathrm{~m}^{3} / \mathrm{s}\right]$ is the inflow into the reservoir, $Q_{\max }\left[\mathrm{m}^{3} / \mathrm{s}\right]$ is the maximum allowable total discharge of the outlets and spillways, $Q_{\min }\left[\mathrm{m}^{3} / \mathrm{s}\right]$ is a constant minimum flow and $S_{\min }\left[\mathrm{m}^{3}\right]$ is the minimum operating volume.

The water supply provided by the reservoir system Lehnmühle-Klingenberg is determined by three supply levels $S_{I}$ to $S_{I I I}$ which are specific for each month and ensure a future deficit probability of $1 \%$.

$Q_{\mathrm{ext}}=\left\{\begin{array}{lr}\left(Q_{\mathrm{ext}}\right)_{S I} & S_{\mathrm{tot}} \geq S_{I}(M) \\ \left(Q_{\mathrm{ext}}\right)_{S I I} & S_{I}(M) \geq S_{\mathrm{tot}} \geq S_{I I}(M) \\ \left(Q_{\mathrm{ext}}\right)_{S I I I} & S_{I I}(M) \geq S_{\mathrm{tot}} \geq S_{I I I}(M) \\ 0.0 \mathrm{~m}^{3} / \mathrm{s} & S_{\mathrm{tot}} \leq S_{\min }\end{array}\right.$

where $\left(Q_{\text {ext }}\right)_{S I-I I I}\left[\mathrm{~m}^{3} / \mathrm{s}\right]$ is the water supply release, $S_{\text {tot }}$ $\left[\mathrm{m}^{3}\right]$ is the total current storage volume of the reservoir system Lehnmühle-Klingenberg and $S_{I-I I I}(M)\left[\mathrm{m}^{3}\right]$ are monthly threshold values of total reservoir volume with $M$ as the month. The highest supply level $\left(Q_{\text {ext }}\right)_{S I}$ amounts to $0.88 \mathrm{~m}^{3} / \mathrm{s}$.

\section{Methodology}

We distinguish between long-term operating rules that govern a reservoir's operation in general and short-term operating rules that come into effect and override the long-term operating rules in the case of a flood event. In order to be able to model the hydrological processes with sufficient accuracy, a time step of one hour is used for the short-term simulations and a time step of one day is used for the long-term simulations, respectively.

\subsection{Reservoir - runoff model}

Rainfall-runoff processes and reservoir operation are simulated using the model BlueM.Sim. This river basin model is capable of simulating complex reservoir operating rules and also comprises conceptual rainfall-runoff and channel routing modules. In the model, operating rules are defined as relationships between system states and reservoir releases. Both linear and non-linear relationships are possible, as well as the definition of reservoir zones (Lohr, 2001).

\subsection{Multi-objective optimization}

A multi-objective optimization problem (MOP) has multiple objective functions which are to be minimized or maximized. The decision variables within a lower and an upper bound constitute a decision variable space. A solution $x$ is a vector of $N$ decision variables $\left(x=x_{1}, \ldots, x_{N}\right)$. The objective functions constitute a multidimensional space called the objective function space. A solution $x$ is called Pareto-optimal when there is no solution $x^{\prime}$ that will improve at least one objective function value without worsening at least one other objective function value.

To solve the MOP, a state-of-the-art Multi-Objective Evolution Strategy algorithm (MOES, Muschalla, 2008) is used. This optimization algorithm, which is based on the concept of domination and Pareto optimality, allows the evaluation of a multitude of objectives and constraints simultaneously. To facilitate the simulation-based evaluation of the objectives mentioned above, the optimization algorithm and the employed simulation model are coupled in a common software shell, providing fully automatic interfaces between the optimization and simulation tools.

The Pareto-optimal set of solutions can be visualized using a so called scatter plot matrix showing all $n \cdot(n-1) / 2$ possible combinations of the objective functions each with a two-dimensional projection of the points of the approximated Pareto-front in the n-dimensional solution space.

The software can be used to find optimal long-term operating rules as well as optimal short-term operating rules in case of flood events including precipitation forecasts.

\section{Optimization of long-term, ecologically oriented reservoir operation}

In this section, we describe how the optimization framework can be used to optimize the long-term operation of the reservoir system Lehnmühle-Klingenberg. In order to improve the ecological performance of the reservoir system, the currently used static operating rules are replaced by dynamic, inflowdriven operating rules and are then optimized with regard to multiple objectives. 


\subsection{Dam-induced hydrologic alteration}

Dams have a multitude of negative environmental impacts (Bunn and Arthington, 2002; Collier et al., 1996; Ligon et al., 1995; Nilsson and Berggren, 2000; Petts, 1984; World Commission on Dams (WCD), 2000). First of all, a stretch of flowing river is converted into an impounded reservoir, thus fundamentally changing the immediate environment of the dam. Secondly, dams act as a barrier between upstream and downstream reaches, inhibiting both the movement of species as well as the transport of sediment, nutrients and organic matter. Thirdly, dams have an effect on water quality, as temperature, suspended sediment, dissolved oxygen and the concentration of other dissolved materials in dam outlets can differ quite strongly from what flows into the reservoir. Finally, with few exceptions (Willmitzer, 2002), most dams profoundly alter the flow regime of the river on which they are built, which has a damaging effect on a large variety of riverine ecosystem functions (Poff et al., 1997, 2007).

In this project, only the latter of these effects - the daminduced hydrologic alteration - is considered, as this is the only effect that is directly influenced by reservoir operation. As Poff et al. (1997) have noted, streamflow, i.e. the flow regime, can be considered a "master variable" that regulates the ecological integrity of flowing water systems, as it also indirectly influences both water quality as well as sediment transport and other ecological aspects.

It should be noted that assessing the hydrologic alteration caused by dam operations is only a first step in a more comprehensive process of modifying dam operations in order to improve ecological dam performance (Richter and Thomas, 2007). However, for rivers where an environmental flow assessment has not yet been carried out and environmental flow requirements have consequently not been established, the reduction of dam-induced hydrologic alteration can serve as an interim goal and as a starting point for an adaptive management process before comprehensive ecosystem research results are available (Richter et al., 1997).

We assess the degree to which a natural flow regime is modified by reservoir operations using the Indicators of Hydrologic Alteration (IHA) (Richter et al., 1996). For this, long-term hydrographs of a "natural" flow regime (either recorded or simulated) are compared to the flow regime produced as a result of reservoir operations in order to calculate the "Hydrologic Alteration" for each of the 33 IHA Parameters.

The Range of Variability Approach (RVA) is then used to define a range of variation in each of the 33 IHA parameters as initial flow management targets. This approach is based on the aquatic ecology theory concerning the critical role of hydrologic variability, and associated characteristics of magnitude, timing, frequency, duration, and rates of change in sustaining aquatic ecosystems (Richter et al., 1996). The fulfillment of these targets represents one of the objectives in the overall optimization problem.

\subsection{Dynamic reservoir operation}

In order to improve the ecological performance of a dam (in terms of hydrologic alteration), it is advantageous to make reservoir releases dependent on the inflow into the reservoir, which in the case of the reservoir system LehnmühleKlingenberg can be regarded as a natural flow regime. This ensures that the existing variability in the natural flow regime is also reflected in the tailwater and avoids the necessity of having to reproduce a natural flow regime artificially.

For this, a dynamic, inflow-driven operating rule was developed which links the discharge from the reservoir $Q_{\text {out }}$ to the current reservoir inflow $Q_{i n}$ by a multiplication factor $f_{\text {dyn }}$. This factor $f_{\text {dyn }}$ is a function of the current storage volume $S$. The general goal of reservoir operations regarding the storage volume is to keep the water level at the top of the normal operating zone, i.e. at the flood guide level $S_{\text {target }}$. When this storage level is reached, outflows should be equal to inflows minus any flows extracted from the system $Q_{\text {ext }}$ (e.g. for water supply). An additional constraint is that releases should not exceed the permitted maximum discharge $Q_{\max }$ (in most cases this will be the no-damage discharge for the tailwater). When the reservoir storage level falls below the flood guide level, outflows should be reduced so as to fill the reservoir again, and above this level, outflows should be increased so as to lower the reservoir level to the target level.

$Q_{\text {out }}= \begin{cases}Q_{i n}, f_{\mathrm{dyn}}(S)-Q_{\mathrm{ext}} & \left(S>S_{\mathrm{min}}\right) \wedge\left(Q_{i n} \cdot f_{\mathrm{dyn}}(S)-Q_{\mathrm{ext}}<Q_{\mathrm{max}}\right) \\ Q_{\max }, & \left(S>S_{\min }\right) \wedge\left(Q_{i n} \cdot f_{\mathrm{dyn}}(S)-Q_{\mathrm{ext}} \geq Q_{\mathrm{max}}\right) \\ Q_{\text {min }}, & \left(S \leq S_{\min }\right)\end{cases}$

The dynamic operating rule is defined by the function $f_{\text {dyn }}(S)$, which in its simplest (linear) form can be described using only two variables (one for the value of $f_{\text {dyn }}$ when the storage volume reaches the dead storage $f_{\text {dyn }}\left(S_{\min }\right)$, and one for the value of $\left.f_{\mathrm{dyn}}\left(S_{\max }\right)\right)$. The factor at $S_{\text {target }}$ is fixed with $f_{\text {dyn }}\left(S_{\text {target }}\right)=1.0$.

\subsection{Optimization}

Dynamic operating rules for the reservoir system Lehnmühle-Klingenberg as described above were implemented in the simulation model BlueM.Sim. Operating rules governing the amount of water extracted from the reservoir system for water supply purposes were left unchanged (see Eq. 2). Additional rules governing water transfers between the two reservoirs were also implemented.

For the optimization, the functions $f_{\text {dyn }}(S)$ are approximated by supporting points with linear interpolation which yields three decision variables for each reservoir. The multiobjective optimization problem consists of four objective functions, which are described in the following.

The first objective is to keep the storage volume $S(t)$ as close as possible to $S_{\text {target }}$. Thus the following objective 
function is formulated for each reservoir:

$\operatorname{Minimize}\left(Z_{\mathrm{dyn}}\right)_{1,2}=\sum_{t=1}^{T}\left(S(t)-S_{\text {target }}\right)^{2}$

where $T$ is the duration of the simulation and $t$ the time step in hours.

The following objective function maximizes the average water supply provision:

$\operatorname{Maximize}\left(Z_{\mathrm{dyn}}\right)_{3}=-\frac{1}{T} \sum_{t=1}^{T} Q_{\text {ext }}(t)$

Due to Eq.(2), the maximum water supply which can be achieved is $\left(Q_{\text {ext }}\right)_{S I}=0.88 \mathrm{~m}^{3} / \mathrm{s}$.

The following objective function specifies that the hydrologic alteration (as a function of the IHA parameters) should be minimized:

$\operatorname{Minimize}\left(Z_{\text {dyn }}\right)_{4}=f($ IHA)

The dead storage volumes are used as constraints.

The evaluation of the objective functions for each parameter set was carried out by simulating a time period of 39 years, using recorded inflows, with a time-step of $24 \mathrm{~h}$. Figure 2 shows a set of 50 Pareto-optimal solutions attained after 5000 simulation runs, depicted in a scatter plot matrix.

Figure 2 shows that ecological performance $\left(Z_{\text {dyn }}\right)_{4}$ and water supply $\left(Z_{\mathrm{dyn}}\right)_{3}$ are clearly competing objectives, while the other objectives seem more or less ambivalent towards each other. For the sake of comparison with the status quo, we have selected solution no. 4528 , which provides the largest amount of water supply with $\left(Z_{\mathrm{dyn}}\right)_{3}=-0.84 \mathrm{~m}^{3} / \mathrm{s}$, which is close to the status quo with $\overline{Q_{\text {ext }}}=-0.87 \mathrm{~m}^{3} / \mathrm{s}$, but exhibits one of the lowest ecological performance values among the solution set. However, even in this - from an ecological viewpoint suboptimal - solution, the dynamic operating rule results in a downstream regime that resembles that of the inflow much more closely; in particular, many of the flow peaks occurring in the inflow also occur in the tailwater (see Fig. 3). This effect is much more pronounced in solutions that exhibit better ecological performance values.

While providing more fluctuation in reservoir releases, the dynamic reservoir operating rule on the other hand causes less fluctuation in reservoir storage levels, as can be seen in Fig. 4.

\section{Short-term optimization using precipitation forecast allowing for uncertainties}

Froehlich et al. (2009) used BlueM.Opt to optimize shortterm operating rules assuming one single precipitation forecast. However, in reality the actual precipitation always deviates from the temporal and spatial precipitation forecast.
Most of the world's major operational weather prediction facilities commonly use ensemble weather prediction and provide warnings of heavy or prolonged rainfall for river basins or special warning regions. An ensemble forecast makes it possible to include a bundle of representative samples of possible future states into the optimization. In this work, an ensemble forecast is approximated by a simple stochastic rainfall generator to show the potential of the proposed optimization method. A future step would be to use real ensemble forecasts from e.g. a national weather service.

An exemplary scenario is presented. It is assumed that a $24 \mathrm{~h}$ forecast with a predicted maximum rainfall amount of $\mathrm{PP}_{\max }=300 \mathrm{~mm}$ is available. The initial hydrological conditions are given, in particular the initial water level of the reservoirs and the initial soil moisture. The rainfall generator is used to create 110 samples of a temporal and spatial rainfall distribution over the river basin of which 33 samples are used for optimization and all 110 samples are used for the validation of the optimized operating policies. In order to consider uncertainties in the fictitious forecast, the maximum rainfall depth of the samples is simply varied between $\mathrm{PP}_{\max }=250, \ldots, 350 \mathrm{~mm}$. The total simulation time is $48 \mathrm{~h}$.

\subsection{Rainfall generator}

In order to model different rainfall scenarios, a stochastic spatial rainfall generator was developed. The precipitation amount is stochastically divided into 6-h intervals based on random numbers. Afterwards, the precipitation amount of each 6-h interval is further divided into 1-h intervals using the same method. An example can be seen in Fig. 5.

The spatial distribution scheme of the rainfall generator consists of one reference station to which the forecasted maximum precipitation amount $\left(\mathrm{PP}_{\mathrm{RS}}\right)$ is applied. Another precipitation station $\left(\mathrm{PP}_{\mathrm{SS}}\right)$, which is located at a maximum distance $\left(D_{\mathrm{SS}}\right)_{\max }$ from the reference station, is used to determine the maximum precipitation reduction. The maximum precipitation reduction is determined by a random number ( $\mathrm{RN})$.

The precipitation of the remaining surrounding stations is interpolated linearly depending on their distance from the reference station $\left(D_{\mathrm{SS}}\right)$. Thus the following equation is applied to each precipitation station:

$\mathrm{PP}_{\mathrm{SS}}=\mathrm{PP}_{\mathrm{RS}}-\frac{\left(\mathrm{PP}_{\mathrm{RS}}-\mathrm{PP}_{\mathrm{RS}} \cdot \mathrm{RN}\right) \cdot D_{\mathrm{SS}}}{\left(D_{\mathrm{SS}}\right)_{\max }}$

After the creation of the precipitation scenario, two plausibility checks are carried out. The first check regards the upper bound. A comparison of the generated precipitation amount at each station and the areal precipitation amount with the probable maximum precipitation according to DVWK (1997b) is considered. The second check considers the relationship between the peak discharge and the flood volume (see Fig. 6). 

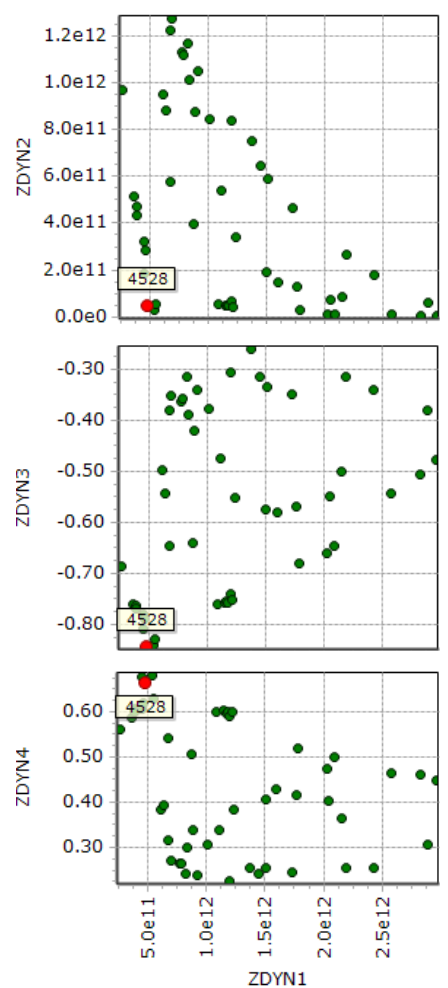

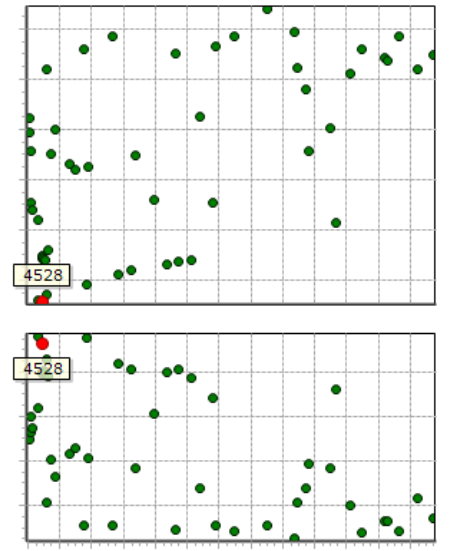

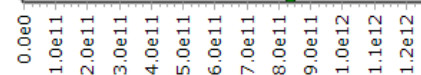

ZDYN2

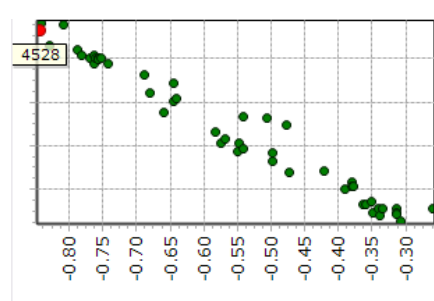

ZDYN3

Fig. 2. Depiction of 50 Pareto-optimal solutions in a scatter plot matrix. Each individual diagram represents one of the possible twodimensional projections of the four-dimensional solution space. Solution no. 4528 is highlighted (red dots). ZDYN1 and ZDYN2 are the sums of the squared storage volume differences of the reservoirs Lehnmühle and Klingenberg to their respective target storage levels, ZDYN3 is the average water supply and ZDYN4 is calculated using IHA parameters.

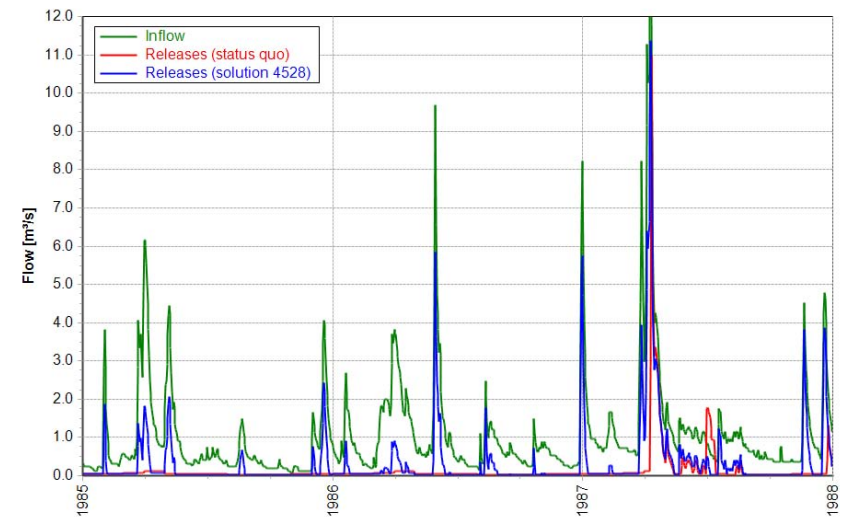

Fig. 3. Reservoir releases as produced by solution no. 4528 compared to reservoir releases from the status quo and reservoir inflows.

\subsection{Optimization}

In each optimization cycle, all simulations with the generated rainfall scenarios are carried out consecutively. The objective functions of every single simulation are squared to give higher objective values a larger weight than smaller objective values. At the end of an optimization cycle, the objective values of each simulation are summed up.

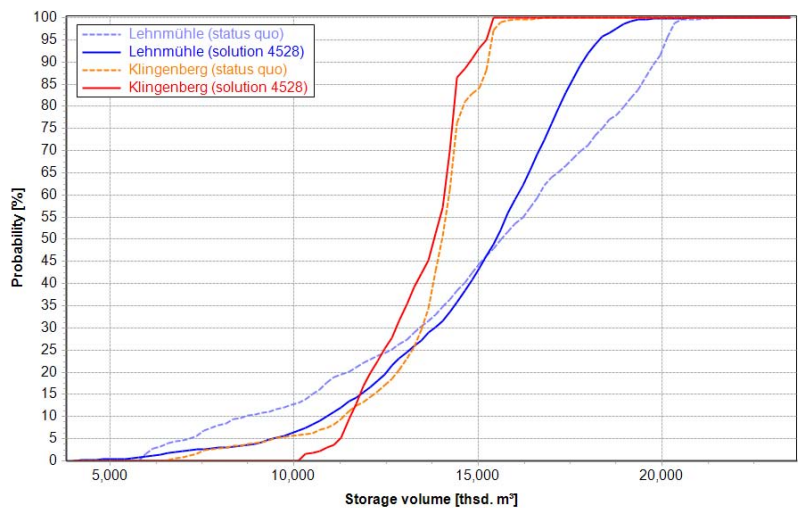

Fig. 4. Cumulative probability distribution of reservoir storage levels (comparison between solution no. 4528 and the status quo).

Damage by inundation $\left(Z_{1}\right)$ is determined using discharge-damage functions for each river section as defined by the system plan of the runoff model; this methodology was proposed by Dittmann et al. (2008). The 

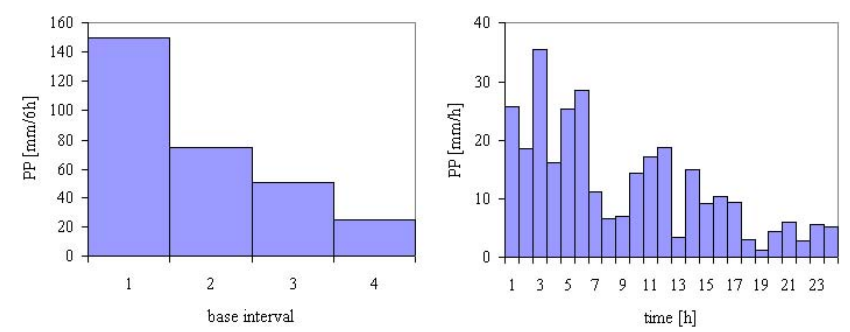

Fig. 5. An exemplary generation of a $24 \mathrm{~h}$ rainfall with $300 \mathrm{~mm}$ is shown. The left graph shows the $6 \mathrm{~h}$ base interval and the right graph the final hourly rainfall.

objective function can be formulated as follows:

Minimize $Z_{1}=\sum_{n=1}^{N} \sum_{k=1}^{K} D_{k}^{2}$

where $N$ is the number of rainfall samples, $K$ is the number of river sections and $D_{k}$ is the damage occurring in each river section.

To minimize the risk due to overtopping, the freeboard $Z_{2,3,4}$ of the three reservoirs is to be maximized. Freeboard is defined as the vertical distance between the dam crest $h_{c}$ and the maximum water level $h_{w}$ in the reservoir. The resulting target objective is:

Minimize $Z_{2,3,4}=\sum_{n=1}^{N} \frac{1}{\left(h_{c}-\left(h_{w}\right)_{\max }\right)^{2}}$

After the optimization, the freeboard of the obtained operating strategies is evaluated by calculating the required freeboard for each of the three reservoirs using wind speed forecasts. The freeboard required to avoid dam overtopping is the sum of wave run-up and wind setup and is calculated according to DVWK (1997b).

During a flood event, the short-term operating rules cause valuable water to be released through the bottom outlet in order to reduce the reservoir level. Thus short-term operating rules also affect water supply safety, especially the current water supply. The objective is to minimize the sum of the reservoir releases through the bottom outlet $Z_{5}$ :

Minimize $Z_{5}=\sum_{n=1}^{N}\left(\sum_{t=1}^{T} Q_{\text {out }}(t)\right)^{2}$

In total, this results in an optimization problem with five objective functions.

\subsection{Modified operating rule}

The reservoir operating rule responsible for keeping the flood retention volume empty can be replaced by a time-dependent release curve and be subjected to optimization. The maximum releases are limited by the hydraulic capacity of the outlets.

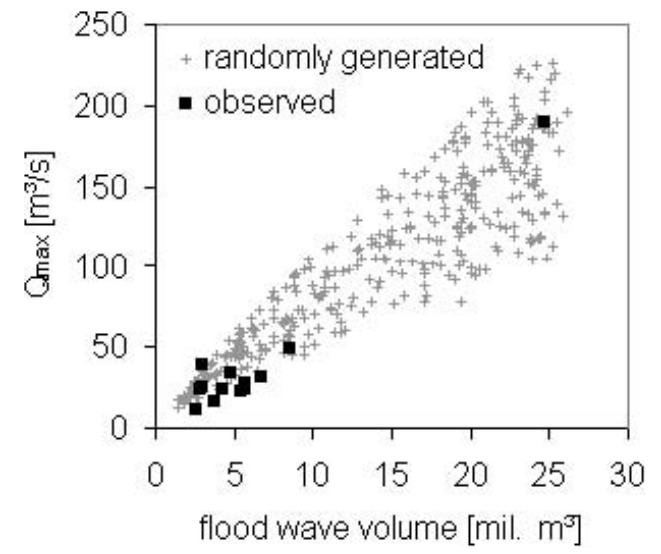

Fig. 6. Comparison of randomly simulated versus measured peak discharge $Q_{\max }$ - flood wave volume relationships at the inflow gauge of reservoir Malter.

Optimizing every single time step would lead to a large number of decision variables and cause long computation times. Investigations by Dittmann et al. (2008) showed that it is sufficient to form the release characteristics by a two-part step function. Release intervals split into more than two intervals do not lead to significantly better optimized solutions. Thus the release curve can be formulated as follows:

$Q_{\text {out }, n}(t)=\left\{\begin{array}{l}Q_{\text {out }, 1} \text { if } t \leq T_{1} \\ Q_{\text {out }, 2} \text { if } t>T_{1}\end{array}\right.$

For each step $n$ the time-dependent release $Q_{\text {out }, n}(t)$ and the release duration $T_{n}$ is optimized. This results in three decision variables for each reservoir - two decision variables for the release amounts $Q_{\text {out, } 1}$ and $Q_{\text {out,2 }}$ and one for the duration of the first step $T_{1}$. The duration of the second step $T_{2}$ is obtained from the total duration $T_{\text {tot }}$ as follows:

$T_{2}=T_{\text {tot }}-T_{1}$

\subsection{Results}

The result of the multi-objective optimization is a set of Pareto-optimal solutions shown in the scatter plot matrix in Fig. 7. To illustrate the results, two solutions L3544 and L4228 are selected in Fig. 7. To validate the selected solutions, a further 77 rainfall samples are simulated. Additionally, two conventional operating strategies comprising a maximum release from the bottom outlet starting from the beginning of the simulation period are considered. Strategy S1 comprises a maximum release only of the reservoir Malter and strategy S2 comprises parallel maximum releases of the reservoirs Malter and Klingenberg.

In comparison to the status quo and the strategies $\mathrm{S} 1$ and S2, the two optimized operating policies L3544 and L4228 clearly minimize the risk of overtopping for all reservoirs (Fig. 9) while at the same time reducing the damage the most (left chart of Fig. 8). 

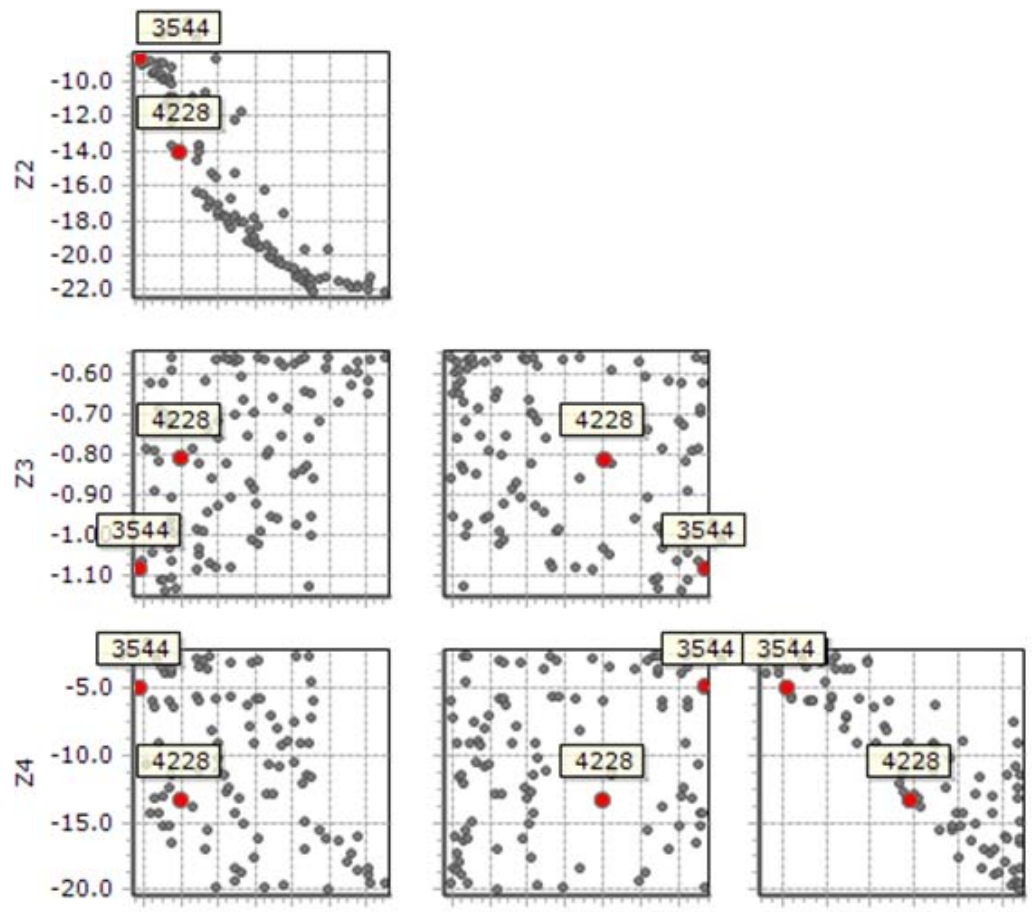

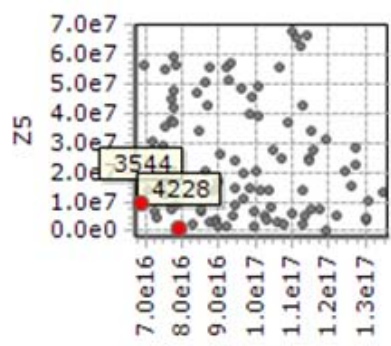

$\mathrm{Z1}$

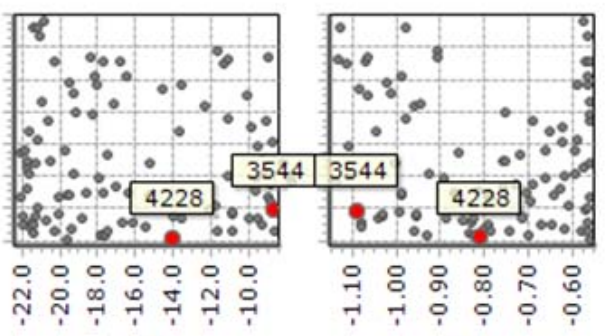

$\mathrm{Z2}$

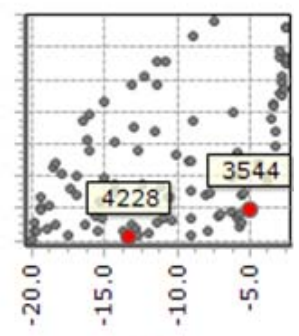

$\mathrm{Z4}$

Fig. 7. Scatter plot matrix: set of Pareto-optimal solutions. The grey dots are the solutions of the five-dimensional Pareto-front. The red dots mark the selected solutions. $Z 1$ Euro $\left.^{2}\right]$ is the squared damage, $Z 2[-\mathrm{m}], Z 3[-\mathrm{m}]$ and $Z 4[-\mathrm{m}]$ the freeboards of the reservoirs Malter, Lehnmühle and Klingenberg respectively and $Z 5$ [mil. $\left.\mathrm{m}^{6}\right]$ is the squared volume of the bottom outlet releases of the reservoir Klingenberg.

It turns out that solution L4228 is superior to the other solutions. Solution L4228 clearly minimizes releases of valuable drinking water from reservoir Klingenberg, leads to the least damage and also minimizes the risk of overtopping at almost all reservoirs.

The presented method for optimizing short-term operating policies is very computationally expensive. The Pareto-front was sufficiently approximated after $10 \mathrm{~h}$ of CPU-time on a Xeon $3.6 \mathrm{GHz}$ computer. Thus the method is restricted in terms of real time optimization but could be used to create a database of robust operating policies. Such a database would contain different pre-optimized operating strategies categorized by initial storage of the reservoirs, initial soil moisture of the river basin and the forecasted length and amount of precipitation.
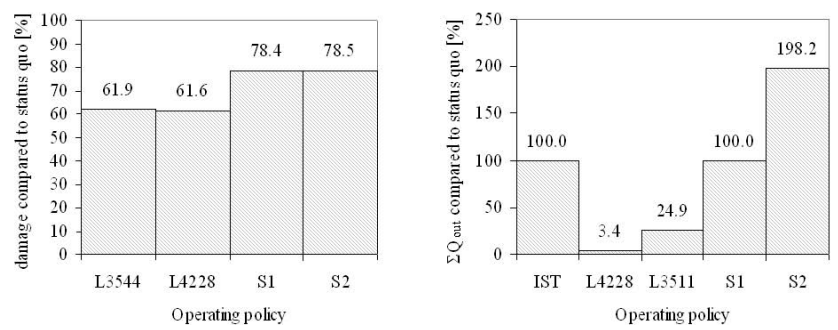

Fig. 8. The results apply to the average downstream damage (left) and the average reservoir releases through the bottom outlet of reservoir Klingenberg (right) of 110 rainfall samples related to the operating policy of status quo. 

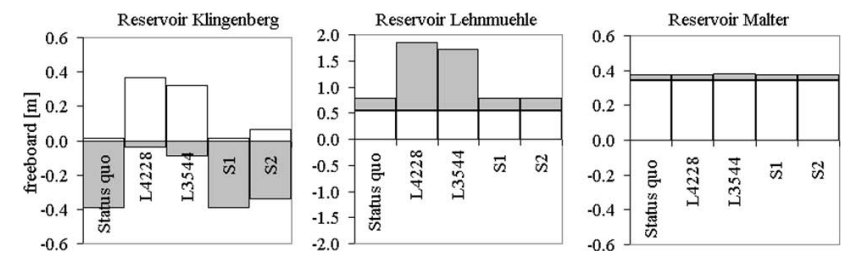

Fig. 9. The results apply to the minimum freeboard from 110 rainfall samples. The extent of the columns marks the required freeboard. The negative parts of the columns (grey colored) mark the extent of the exceedance of the required freeboard.

\section{Conclusions}

The described multi-objective optimization algorithm can be used for optimizing reservoir operation regarding both eventbased as well as normal long-term operations. The result of the optimization is a set of most effective compromises between the target objectives, which exposes conflicting objectives and allows for transparent decision-making.

The described dynamic operating rule on the one hand produces less fluctuation in reservoir storage levels, and on the other hand results in a downstream regime that more closely resembles that of the natural inflow. From an ecological viewpoint, these are both positive effects. In the case study presented here, these effects could only be achieved in conjunction with a small reduction in water supply provisions.

The described optimization of event-based reservoir operation can also be used for implementing real-time flood control based on continuously updated precipitation forecasts.

Edited by: B. Merz

Reviewed by: M. Aufleger and two other anonymous referees

\section{References}

Bunn, S. E. and Arthington, A. H.: Basic Principles and Ecological Consequences of Altered Flow Regimes for Aquatic Biodiversity, Environ. Manage., 30(4), 492-507, 2002.

Chen, L., McPhee, J., and Yeh, W. W.: A diversified multiobjective GA for optimizing reservoir rule curves, Adv. Water Resour., 30(5), 1082-1093, 2007.

Collier, M., Webb, R., and Schmidt, J.: Dams and Rivers - A Primer on the Downstream Effects of Dams, US Geological Survey, ISBN 0788126989, 1996.

Dittmann, R., Froehlich, F., Pohl, R., and Ostrowski, M. W.: A Management System for Optimizing the Operating Rules of Multipurpose Reservoirs during Extreme Floods under Consideration of Ecological Aspects, in: 4th International Symposium on Flood Defence, Toronto, Canada, 2008.

Froehlich, F., Dittmann, R., Ostrowski, M. W., and Pohl, R.: Optimierung von Mehrzweckspeichern im Hinblick auf Hochwasserrisiko und Ökologie, Hydrol. Wasserbewirts., 53(3), 146-153, 2009.
DVWK: Maximierte Gebietsniederschlagshöhen für Deutschland, DVWK Deutscher Verband für Wasserwirtschaft und Kulturbau e.V., Bonn, 1997a.

DVWK: Freibordbemessung an Stauanlagen, DVWK Deutscher Verband für Wasserwirtschaft und Kulturbau e.V., Bonn, ISBN 978-3-935067-92-8, 1997b.

Kim, T., Heo, J., and Jeong, C.: Multireservoir system optimization in the Han River basin using multi-objective genetic algorithms, Hydrol. Process., 20(9), 2057-2075, 2006.

Labadie, J. W.: Optimal operation of multireservoir systems: stateof-the art-review, J. Water Res. Pl.-ASCE, 130(2), 93-111, 2004

Ligon, F., Dietrich, W., and Trush, W.: Downstream Ecological Effects of Dams - A geomorphic perspective, BioScience, 45(3), 183-192, 1995.

Lohr, H.: Simulation, Bewertung und Optimierung von Betriebsregeln für wasserwirtschaftliche Speichersysteme, Ph.D. thesis, Technische Universität Darmstadt, Institut für Wasserbau und Wasserwirtschaft, 2001.

Muschalla, D.: Optimization of integrated urban wastewater systems using multi-objective evolution strategies, Urban Water J., 5(1), 59-67, 2008.

Ndiritu, J. G.: Maximising water supply system yield subject to multiple reliability constraints via simulation-optimisation, Water SA, 31(4), 423-434, 2005.

Nilsson, C. and Berggren, K.: Alterations of Riparian Ecosystems Caused by River Regulation, BioScience, 50(9), 783-792, 2000.

Oliveira, R. and Loucks, D. P.: Operating Rules for Multireservoir Systems, Water Resour. Res., 33(4), 839-852, 1997.

Petts, G.: Impounded Rivers: Perspectives for Ecological Management, John Wiley and Sons, Chichester, England, ISBN 0-47113006-3, 1984.

Poff, N. L., Olden, J. D., Merritt, D., and Pepin, D.: Homogenization of regional river dynamics by dams and global biodiversity implications, P. Natl Acad. Sci. USA, 104, 5732-5737, 2007.

Poff, N., Allan, J., Bain, M., Karr, J., Prestegaard, K., Richter, B., Sparks, R., and Stromberg, J.: The Natural Flow Regime, BioScience, 47(11), 769-784, 1997.

Richter, B., Baumgartner, J., Powell, J., and Braun, D.: A Method for Assessing Hydrologic Alteration within Ecosystems, Conserv. Biol., 10(4), 1163-1174, 1996.

Richter, B., Baumgartner, J., Wigington, R., and Braun, D.: How much water does a river need?, Freshwater Biol., 37(1), 231249, 1997.

Richter, B. D. and Thomas, G. A.: Restoring Environmental Flows by Modifying Dam Operations, Ecol. Soc., 12(1), 26 pp., 2007.

Sharif, M. and Wardlaw, R.: Multireservoir Systems Optimization Using Genetic Algorithms: Case Study, J. Comput. Civil Eng., 14(4), 255-263, 2000.

Willmitzer, H.: The Construction of the Leibis-Lichte Dam: Ecological Influences and Possibilities of There [sic] Minimisation, Deutsches Talsperrenkommitee (DTK), 2002.

World Commission on Dams (WCD): Dams and development: a new framework for decision-making, Earthscan, London, UK, 2000.

Yeh, W.: Reservoir management and operation models: A state-ofthe-art review, Water Resour. Res., 21(12), 1797-1818, 1985. 